\title{
Hypotensive effects of resistance exercises performed at different intensities and same work volumes
}

\author{
Marcos Doederlein Polito ${ }^{1,2}$, Roberto Simão ${ }^{1,2,3}$, Gilmar Weber Senna ${ }^{3}$ and Paulo de Tarso Veras Farinatti ${ }^{2}$
}

\begin{abstract}
The aim of this paper was to compare the effects of two sequences of resistance exercises (RE), with different intensities but same training volume, on post-exercise blood pressure responses. Sixteen young subjects with previous experience in RE were evaluated during three non-following days in chest press, legpress, pulley pull down, leg curl, shoulder press, and biceps curl. On the first day, the load associated with six maximal repetitions (6RM) were determined for each exercise. On the second day, three sets of 6RM were performed (SEQ6), with a two minute interval between the sets. On the last day, the same procedure was repeated, but using 12 repetitions with $50 \%$ of $6 \mathrm{RM}$ load (SEQ12). Rest BP was measured before the sequences by auscultatory method. Post-exercise resting BP was measured each 10 minutes by ambulatory BP monitoring during 60 minutes. The magnitude and duration of BP variability were compared by repeated ANOVA measures followed by Tuckey post-hoc test $(p<0.05)$. A significant reduction in diastolic blood pressure (DBP) was observed in the first $20 \mathrm{~min}$ utes after SEQ12, but not after SEQ6. SEQ12 elicited significant decline in systolic blood pressure (SBP), at least during the first 50 minutes after the exercise, while significant reductions were observed in all measures after SEQ6. There were no significant differences between the absolute values of DBP and SBP after both sequences. In conclusion: a) RE had hypotensive effects on blood pressure, main-

1. Programa de Pós-Graduação em Educação Física - Universidade Gama Filho.

2. Laboratório de Atividade Física e Promoção da Saúde - Universidade do Estado do Rio de Janeiro.

3. Universidade Católica de Petrópolis.

Received in 23/11/02
\end{abstract}

Approved in $8 / 3 / 03$

Correspondence to:

Marcos Polito

Laboratório de Atividade Física e Promoção da Saúde - Labsau

Universidade do Estado do Rio de Janeiro

Rua São Francisco Xavier, 524, sala 8.133, bloco F, Maracanã

20550-013 - Rio de Janeiro, RJ

E-mail: mdpolito@uol.com.br ly SBP; b) the absolute decline of SBP seem not to be influenced by different interactions between workload and number of repetitions; c) higher workloads seem to extend the total time of SBP post-exercise reduction; d) the number of repetitions seems to have more influence on DBP than SBP, but for a short period of time.

Key words: Blood pressure. Hypotension. Weight lifting. Health.

\section{INTRODUCTION}

Heart disease is the main cause of death in the US ${ }^{1}$. In Brazil, cardiovascular conditions are the main cause of deaths, with a mortality rate of $32.6 \%{ }^{2}$. One of the main risk factors for a heart disease is hypertension. Lowering blood pressure (BP), even in normotense subjects, is important in reducing the risk of heart disease ${ }^{3}$. The regular practice of exercises aids the reduction of resting BP in two ways. The first is a hypotensive post-exercise effect, which means resting BP levels would decrease once the effort is over ${ }^{4}$. This response takes place over hours after the exercise practice is ended ${ }^{5}$, and may last for a few days ${ }^{6}$. Another way BP is reduced is by chronic response due to the continuing practice of physical activity.

There is consensus in the literature about rest-related BP chronic reduction through aerobic exercises ${ }^{1,7,8}$. About resistance exercises, some data show that continuing training can either decrease ${ }^{9-11}$ or maintain BP levels ${ }^{12,13}$. As to decreasing BP levels immediately after physical activity, there are consistent evidences that the reduction is induced by aerobic exercise, considering intensity ${ }^{14}$, age group ${ }^{15,16}$, gender ${ }^{17}$, duration ${ }^{18}$, and muscular mass ${ }^{19}$.

On the other hand, information on hypotensive effects after resistance exercises are somewhat scarce. During this type of activity, BP tends to raise rapidly, and may reach high levels ${ }^{20-22}$. The magnitude of the load and the muscular mass involved may be determinant for such gradient ${ }^{23,24}$. However, the behavior of BP levels soon after resistance exercises is not well defined in the literature. While some studies show decrease in BP levels after the exercises ${ }^{25,26}$, others do not report changes ${ }^{27}$ or report BP increase ${ }^{28}$. 
Thus, the purpose of this study was to compare postexercise BP levels over 60 minutes, between two sessions of resistance exercises, performed under different intensities but with the same load:repetition ratio (training volume), between the sessions.

\section{METHODS}

Sixteen volunteers were studied, being 9 males $(20 \pm 1$ years old; $68 \pm 11 \mathrm{~kg} ; 173 \pm 7 \mathrm{~cm})$ and 7 females $(21 \pm 5$ years old; $53 \pm 6 \mathrm{~kg} ; 164 \pm 5 \mathrm{~cm}$ ). All of them had been practicing resistance exercises for, at least, 6 months. This criterium was adopted to prevent occurrence of late muscular pain, and errors in establishing the workload due to lack of necessary coordination to perform the exercises. Exclusion criteria were the use of ergogenic substances; bone, muscle or joint impairment that totally or partially prevented performance of the exercises, the use of medication that affected resting or under exercise BP values, intake of caffeine or alcoholic beverages on data collection day, and performance of a daily activity that demanded high energy. All subjects signed the informed consent form after the trial had been approved by the Ethics Committee of the Institution.

Each subject made three, non-consecutive visits to the study site. First, 6 maximal repetition (6MR) tests were performed for the following exercises: chest press, legpress, pulley pull down, leg curl, shoulder press, and biceps curl. On the second day, the exercises were performed in three sets of 6MR, with a two-minute interval between the sets (SEQ6). On the last day, the procedure was the same, except that the number of repetitions was 12 , and the load was half of that of the 6MR (SEQ12). This allowed the same work volume to be kept for each set, considering the load:repetition ratio. Thus, the total weight was the same for each day, but the intensity of the exercises was differ- ent. In performing both sequences of exercises, subjects were instructed not to do the Valsalva maneuver. Prior to beginning the workout on the second and third day, BP was measured by a trained evaluator using auscultatory method, once the subject had been seated and quiet for $10 \mathrm{~min}$ utes. After each sequence was finished, BP was recorded in a 10-minute cycle by ambulatory monitoring (ABPM), with the subject in total rest for 60 minutes (Spacelabs Medical, Redmond, WA, USA).

For data analysis, ANOVA two-way with repeated measures was used followed by Tukey post-hoc test to compare systolic and diastolic BP for the different exercises. Statistical analysis compared the systolic and diastolic BP values for each sequence against resting, considering $\mathrm{p}<$ 0.05 as statistically significant.

\section{RESULTS}

The table 1 presents mean SBP and DBP in rest and after each sequence of exercises. No significant differences were found between post-exercise SBP and DBP when sequences were compared, and they were not associated to significantly higher BP levels than those of resting. It was also noted that SBP was lowered in all measurements, whereas SEQ12 was associated to SBP reduction for a period of time no longer than 50 minutes. As to DBP, SEQ12 caused significant reduction in less than 20 minutes after ending the exercise, whereas SEQ6 did not induce significant changes. For a better visualization, figures 1 and 2 show progression of SBP and DBP in rest and after the sequences of exercises, respectively.

\section{DISCUSSION}

Some studies failed to demonstrate hypotensive effect from this type of activity, regardless of subject fitness and gender. O'Connor et al. ${ }^{28}$, for instance, have observed SBP

TABLE 1

Mean values ( \pm standard deviation) for systolic and diastolic blood pressure after the end of each sequence

\begin{tabular}{|c|c|c|c|c|}
\hline & \multicolumn{2}{|c|}{ SBP } & \multicolumn{2}{|c|}{ DBP } \\
\hline & SEQ6 & SEQ12 & SEQ6 & SEQ12 \\
\hline Resting & $108.8 \pm 10.6$ & $105.1 \pm 7.2$ & $65.4 \pm 6.4$ & $66.9 \pm 6.3$ \\
\hline $10 \mathrm{~min}$. & $93.5 \pm 7.2 *$ & $93.5 \pm 8.6^{*}$ & $60.9 \pm 6.2$ & $60.4 \pm 5.5^{*}$ \\
\hline $20 \mathrm{~min}$. & $95.4 \pm 8.0 *$ & $94.0 \pm 9.9 *$ & $62.0 \pm 6.2$ & $62.6 \pm 7.0$ \\
\hline $30 \mathrm{~min}$. & $94.1 \pm 7.6 *$ & $95.6 \pm 9.1^{*}$ & $61.9 \pm 4.6$ & $62.4 \pm 4.5$ \\
\hline $40 \mathrm{~min}$. & $96.5 \pm 7.6 *$ & $97 \pm 8.3^{*}$ & $64.8 \pm 5.7$ & $62.4 \pm 3.7$ \\
\hline $50 \mathrm{~min}$. & $99.4 \pm 6.1^{*}$ & $100.4 \pm 6.9$ & $64.9 \pm 3.8$ & $66.4 \pm 5.0$ \\
\hline $60 \mathrm{~min}$. & $100.3 \pm 7.5^{*}$ & $99.6 \pm 9.3$ & $68.3 \pm 6.8$ & $66.0 \pm 5.6$ \\
\hline
\end{tabular}




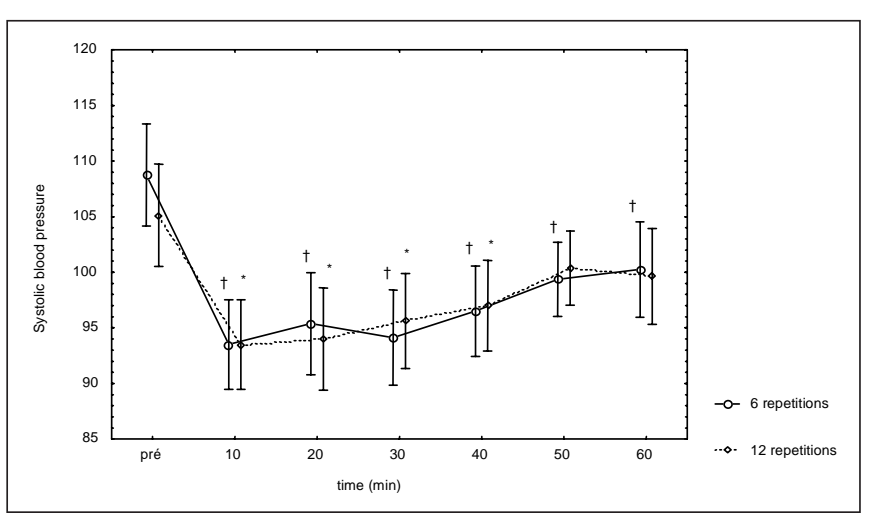

Fig. 1 - Behavior of systolic blood pressure before and after the sequences

increase within 15 minutes after a sequence performed by females at $80 \%$ of $1 \mathrm{MR}$ load. Hill et al. ${ }^{29}$ noted an important $\mathrm{BP}$ reduction in trained males immediately after performing resistance exercises, but in a few minutes BP levels reached pre-exercise levels, which were maintained over the 60 minutes of monitoring. Recently, Roltsch et al. ${ }^{21} \mathrm{did}$ not identify significant BP level changes after resistance exercises performed by normotense males and females, both sedentary or physical exercise practitioners. In this study, BP was assessed by 24-h ABPM. It is possible that a resistance exercise session may not trigger significant BP reduction for a somewhat lengthy period of time, which can explain the results of this study.

However, some evidences show significant BP reduction immediately after resistance exercises are finished. In Hardy's and Tucker's study ${ }^{25}$, for instance, ABPM identified SBP and DBP reduction for, at least, 1 hour after a resistance exercises session, in 24 males. In our trial, we noted a lengthy post-exercise reduction of SBP only. This could be explained, in part, by the features of the sample. We used healthy, trained subjects, whereas Hardy and Tucker ${ }^{25}$ studied sedentary, hypertensive subjects. It is known that higher BP reductions after aerobic workout tend to be typical of hypertensive individuals ${ }^{6}$, and it is likely that the same occurs for resistance exercises. However, studies involving populations of hypertensives and their performance of resistance exercises are relatively scarce, and do not allow further inferences ${ }^{10}$. It is expected, however, that BP reduction in healthy individuals occurs similarly in hypertensives, as shown by Fisher's study ${ }^{26}$ with normotensive and hypertensive females, after performing 15 repetitions of 5 sequential exercises at $50 \%$ of $1 \mathrm{MR}$ load. Post-exercise BP was recorded over 60 minutes, and only SBP was significantly reduced. Our data support Fisher ${ }^{26}$ outcomes, that found significant SBP decrease also for exercises of some-

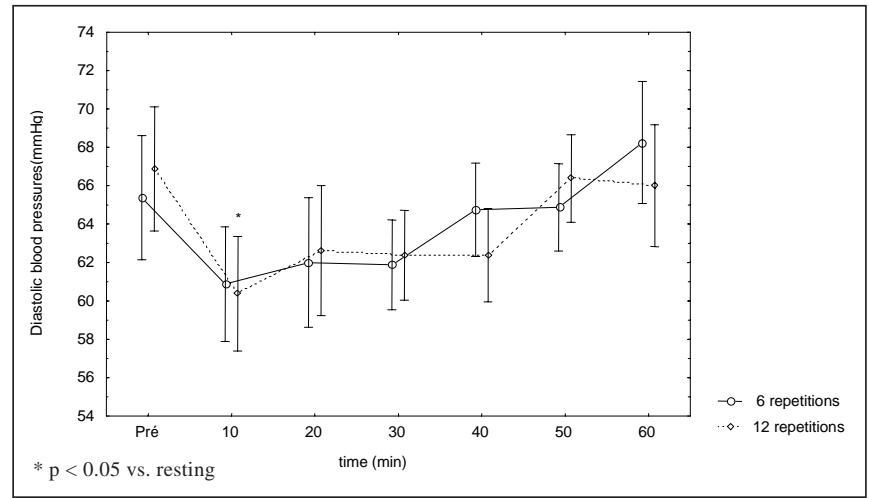

Fig. 2 - Behavior of diastolic blood pressure before and after the sequences

what low intensity. As that author did not compare BP reduction to other intensities, a more detailed comparison of the outcome for both trials is compromised.

Anyway, high-intensity resistance exercises do not seem to be associated to higher post-exercise BP reductions, like somewhat lesser strain with higher number of repetitions (SEQ6 x SEQ12). In our trial, no differences in SBP and DBP were found for the two training sequences. This fact had already been reported by Brown et al. ${ }^{30}$, who did not find BP changes over 1 hour when sequences using $40 \%$ and $70 \%$ of 1 MR with $20-25$ and 8-10 repetitions, respectively, were compared. On the other hand, in spite of the similar behaviors of SBP and DBP under different intensities, some trials could not prove any post-resistance exercises hypotensive effect. Focht and Koltyn ${ }^{31}$, for instance, could only note DBP reduction for 20 minutes after a sequence performed at $50 \%$ of $1 \mathrm{MR}$ in 84 individuals, and no changes were found at $80 \%$ of $1 \mathrm{MR}$. Our results partially agree with these data: DBP reduction was also seen in a less intense sequence, for a similar period of time. It is likely that Focht and Koltyn ${ }^{31}$ did not reach more significant results because BP was measured in long intervals (20, 60 and 120 minutes after the exercise).

To conclude, our results suggest that intensity of resistance exercises may influence the duration of hypotensive effect once that activity is over, but not the magnitude of such reduction. Apparently, more intense sessions could promote a longer period of SBP reduction. Less intense sessions could reduce DBP for a somewhat short period, whereas a more strenuous workout would not change acute responses. Other trials should be carried out to confirm these results and expand them to other exercises, including the control of potentially intervening variables, such as muscular mass, velocity of execution, and associated aerobic training. 


\section{REFERENCES}

1. Whelton SP, Chin A, Xin X, He J. Effect of aerobic exercise on blood pressure: a meta-analysis of randomized, controlled trials. Ann Intern Med 2002;136:493-503.

2. Fundação Nacional de Saúde. Sistemas de informações de mortalidade: mortalidade proporcional por grupos de causas determinadas (indicador RIPSA C7), Brasil, 1998. Disponível em www.funasa.gov.br.

3. Vasan RS, Larson MG, Leip EP, Evans JC, O’Donnell CJ, Kannel WB, et al. Impact of high-normal blood pressure on the risk of cardiovascular disease. N Engl J Med 2001;345:1291-7.

4. MacDonald JR. Potential causes, mechanisms, and implications of post exercise hypotension. J Hum Hypertens 2002;16:225-36.

5. Thompson PD, Crouse SF, Goodpaster B, Kelley D, Moyna N, Pescatello L. The acute versus chronic response to exercise. Med Sci Sports Exerc 2001;33:S438-45.

6. Araújo CG. Fisiologia do exercício físico e hipertensão arterial: uma breve discussão. Hipertensão 2001;4:78-83.

7. Kelley G, McClellan P. Antihypertensive effects of aerobic exercise. A brief meta-analytic review of randomized controlled trials. Am J Hypertens 1994;7:115-9.

8. Kokkinos PF, Narayan P, Colleran JA, Pittaras A, Notargiacomo A, Reda $\mathrm{D}$, et al. Effects of regular exercise on blood pressure and left ventricular hypertrophy in African-American men with severe hypertension. $\mathrm{N}$ Engl J Med 1995;333:1462-7.

9. Martel GF, Hurlbut DE, Lott ME, Lemmer JT, Ivey FM, Roth SM, et al. Strength training normalizes resting blood pressure in 65 - to 73 year-old men and women with high normal blood pressure. J Am Geriatr Soc 1999;47:1215-21.

10. Kelley GA, Kelley KS. Progressive resistance exercise and resting blood pressure: a meta-analysis of randomized controlled trials. Hypertension 2000;35:838-43.

11. Byrne HK, Wilmore JH. The effects of resistance training on resting blood pressure in women. J Strength Cond Res 2000;14:411-8.

12. Fleck SJ. Cardiovascular adaptations to resistance training. Med Sci Sports Exerc 1988;20:S146-51.

13. Hagerman FC, Walsh SJ, Staron RS, Hikida RS, Gilders RM, Murray $\mathrm{TF}$, et al. Effects of high-intensity resistance training on untrained older men. I. Strength, cardiovascular, and metabolic responses. J Gerontol A Biol Sci Med Sci 2000;55:B336-46.

14. Forjaz CL, Matsudaira Y, Rodrigues FB, Nunes N, Negrão CE. Postexercise changes in blood pressure, heart rate and rate pressure product at different exercise intensities in normotensive humans. Braz J Med Biol Res 1998;31:1247-55.

15. Taylor-Tolbert NS, Dengel DR, Brown MD, McCole SD, Pratley RE, Ferrel RE, et al. Ambulatory blood pressure after acute exercise in older men with essential hypertension. Am J Hypertens 2000;13:44-51.
16. Vriz O, Mos L, Frigo G, Sanigi C, Zanata G, Pegoraro F, et al. Effects of physical exercise on clinic and 24-hour ambulatory blood pressure in young subjects with mild hypertension. J Sports Med Phys Fitness 2002; 42:83-8.

17. Senitko AN, Charkoudian N, Halliwill JR. Influence of endurance exercise training status and gender on post-exercise hypotension. J Appl Physiol 2002;92:2368-74.

18. MacDonald JR, MacDougall JD, Hogben CD. The effects of exercise duration on post-exercise hypotension. J Hum Hypertens 2000;14:1259.

19. MacDonald JR, MacDougall JD, Hogben CD. The effects of exercising muscle mass on post exercise hypotension. J Hum Hypertens 2000;14: 317-20.

20. MacDougall JD, Tuxen D, Sale DG, Moroz JR, Sutton JR. Arterial blood pressure response to heavy resistance exercise. J Appl Physiol 1985;58: 785-90.

21. Fleck SJ, Dean LS. Resistance-training experience and the pressor response during resistance exercise. J Appl Physiol 1987;63:116-20.

22. Gotshall R, Gootman J, Byrnes W, Fleck S, Valovich T. Noninvasive characterization of the blood pressure response to the double-leg press exercise. JEPonline 1999;2:1-6.

23. Benn SJ, McCartney N, McKelvie RS. Circulatory responses to weight lifting, walking, and stair climbing in older males. J Am Geriatr Soc 1996;44:121-5.

24. Bermon S, Rama D, Dolisi C. Cardiovascular tolerance of healthy elderly subjects to weight-lifting exercises. Med Sci Sports Exerc 2000; 32:1845-8.

25. Hardy DO, Tucker LA. The effects of a single bout of strength training on ambulatory blood pressure levels in 24 mildly hypertensive men. Am J Health Promot 1999;13:69-72.

26. Fisher MM. The effect of resistance exercise on recovery blood pressure in normotensive and borderline hypertensive women. J Strength Cond Res 2001;15:210-6.

27. Roltsch MH, Mendez T, Wilund KR, Hagberg JM. Acute resistive exercise does not affect ambulatory blood pressure in young men and women. Med Sci Sports Exerc 2001;33:881-6.

28. O'Connor PJ, Bryant CX, Veltri JP, Gebhardt SM. State anxiety and ambulatory blood pressure following resistance exercise in females. Med Sci Sports Exerc 1993;25:516-21.

29. Hill DW, Collins MA, Cureton KJ, DeMello J. Blood pressure response after weight training exercise. J Strength Cond Res 1989;3:44-7.

30. Brown SP, Clemons JM, He Q, Liu S. Effects of resistance exercise and cycling on recovery blood pressure. J Sports Sci 1995;12:463-8.

31. Focht BC, Koltyn KF. Influence of resistance exercise of different intensities on state anxiety and blood pressure. Med Sci Sports Exerc 1999; 31:456-63. 